\title{
aniki
}

Revista Portuguesa da Imagem em Movimento Portuguese Journal of the Moving Image

\section{A escola francesa de som direto: Antoine Bonfanti e Paul Vecchiali, o caso Femmes, femmes (1974)}

\author{
Sérgio Puccini Soares ${ }^{1}$
}

\section{Introdução}

O artigo apresenta uma análise sobre o tratamento sonoro do filme Femmes, femmes (1974), dirigido pelo cineasta francês Paul Vecchiali. Nesse filme, Vecchiali opta por uma radical valorização do som direto, o som obtido em situação de filmagem, contando, para tanto, com a significativa contribuição do técnico de som Antoine Bonfanti. Este artigo parte da premissa de que, ao analisarmos aspectos técnicos, que condicionam aspectos estéticos do filme, é imprescindível ampliarmos o centro de nosso interesse a fim de incluirmos os profissionais técnicos envolvidos na produção. O que se busca é a valorização do papel desses profissionais, entendidos também como profissionais de criação. Dessa forma, o nome de Antoine Bonfanti ocupa posição central na análise. Muitas das considerações feitas aqui são baseadas em depoimentos de Bonfanti, que refletem suas concepções acerca do som de cinema. Com isso pretendemos reforçar um campo ainda pouco explorado nos estudos de cinema, o estudo dos técnicos, das técnicas e das tecnologias do cinema, mas que vem ganhando corpo muito em função do interesse de pesquisadores ligados à área da historiografia, como Vincent Bouchard, Priska Morrisey, Martin Barnier, Laurent Mannoni, Rafael de Luna Freire, Luís Alberto Rocha Melo, James Lastra, André Gaudreault, entre outros. Há que chamar a atenção ainda para o fato de que os técnicos de som são figuras quase ausentes das análises de filmes, especialmente aquelas que abordam o cinema direto, que invariavelmente acabam valorizando mais aspectos da imagem do que do som².

Conforme pretendemos demonstrar ao longo do artigo, o pensamento de Bonfanti sobre o som no cinema se insere dentro de um contexto marcado pelas inovações tecnológicas de som e imagem no início dos anos 1960 (câmeras leves de 16mm, gravadores de áudio magnéticos e portáteis, etc.), que irão impulsionar toda uma geração de cineastas a deixarem os ambientes controlados dos estúdios na

\footnotetext{
${ }^{1}$ Universidade Federal de Juiz de Fora, Campus Universitário, Rua José Lourenço Kelmer, s/n - São Pedro, Juiz de Fora - Minas Gerais, CEP 36036-900, Brasil. ${ }^{2}$ Sobre esse assunto, ver, por exemplo, Marsolais (1974), Mamber (1974) e Gauthier et al. (2003).
} 
busca da "espontaneidade" ${ }^{3}$ dos acontecimentos de rua, das situações de mundo captadas em rodagens externas. As novas possibilidades de captação de som, a partir de equipamentos portáteis, fomentarão toda uma escola de som direto na França ${ }^{4}$ que terá em Bonfanti um dos principais nomes. Curiosamente, na França, essa escola de som direto será tributária a uma tradição iniciada nos anos 1930, que terá em Jean Renoir seu maior avalista.

\section{Antoine Bonfanti e a tradição do som direto na França}

Desde meados da década de 1980 que Michel Chion (1985; 2002) problematiza o que ele chama de uma abordagem "monolítica" adotada pelo cinema contemporâneo francês que entende que "não existe bom som que não o som verdadeiro da filmagem" (Chion 2002, 77). ${ }^{5}$ Para Chion, essa visão impede que os realizadores explorem mais as potencialidades do som, empobrecendo o repertório sonoro dos filmes franceses, algo que contradiz uma tradição de nomes como Robert Bresson, Jacques Tati, Jean Renoir e Jean-Luc Godard. Diz Chion:

Filmar em som direto é portanto um pouco a doxa na França. Muitos realizadores, como eu já disse antes, fazem disso uma questão de princípio, antes mesmo de haver testado possibilidades diferentes. As outras soluções são frequentemente descartadas desde saída como se rompessem a autenticidade da atuação. (Chion 2002, 78)

Uma das consequências desse apego ao som direto será aquilo a que Chion $(1985,204)$ chamou "um ruído exaustivo" que busca unicamente satisfazer a "lógica do naturalismo". Para aqueles que buscam justificar a escolha recorrendo à tradição do som direto em Renoir, Chion lembra que, aí, as filmagens ocorriam, na maior parte das vezes, dentro de estúdios silenciosos. Mesmo quando estas se faziam em contexto externa, os ambientes urbanos da França dos anos 1930 eram bem menos barulhentos do que nos dias atuais (Chion 1985, 207). Para o autor, trata-se, antes de tudo, de um problema da concepção do som do filme que em nada tem que ver com a inegável qualidade dos técnicos de som direto envolvidos nas produções, tais como Jacques Maumont, Luc Perini, Michel Fano, Jean-Pierre Ruh e Antoine Bonfanti - nomes que ajudaram a consolidar toda uma escola de som direto na França a partir dos anos 1960, muito a partir da experiência adquirida em produções de documentários. Para este artigo, nosso interesse estará voltado para o trabalho de Bonfanti, mais especificamente aquele desempenhado em parceria com o cineasta Paul Vecchiali, a partir da análise do filme Femmes, femmes $(1974)^{6}$.

\footnotetext{
${ }^{3}$ Tomando emprestado a expressão de David Neves (1966).

${ }^{4}$ Michel Marie (2013) apresenta um bom panorama de cineastas e filmes diretamente ligados à escola de som direto.

${ }^{5}$ Todas as traduções das citações apresentadas no artigo foram feitas pelo autor.

${ }^{6}$ Parte do material de pesquisa apresentado neste artigo foi fruto de estágio de pós-doutorado realizado junto à Universidade Sorbonne Nouvelle - Paris 3, entre
} 
O valor de "verdade", conforme comentado por Chion (2002, 77) em relação ao som direto, orientou as preocupações de Antoine Bonfanti desde Le joli mai, filme de Chris Marker e Pierre Lhomme (1963) que marca sua descoberta do som direto após um período trabalhando dentro de estúdios de som e mixagem como MGM/FR e SIMO. Em depoimento prestado para o documentário de Suzanne Durand (2002), o cineasta André Delvaux comenta que Bonfanti "foi um fanático do som direto, do som real, seja no documentário ou, sobretudo, no cinema de ficção". Muito embora o trabalho de Bonfanti não se limitasse à captação de som direto, mas também avançasse para o trabalho de mixagem em estúdios, ele será creditado como o principal iniciador da escola de som direto que se consolida na França nos anos 1960/70. Como afirma Jean-Pierre Ruh: "A escola do som direto é francesa, ela se inicia com Antoine Bonfanti. Seguiram Bernard Aubouy, Pierre Gamet, Pierre Lenoir, eu mesmo. Nós adquirimos no campo um conhecimento, uma desenvoltura" (Segura e Mouriès 2005, 41).

A participação decisiva e incansável de Bonfanti em filmeschave do cinema francês desde os anos 1960, tais como Muriel (Resnais 1962), La jetée (Marker 1963), Pierrot le fou (Godard 1965) e India song (Duras 1975), somados à dedicação no trabalho de formação de novos técnicos em escolas como o Institut National Supérieur des Arts du Spectacle et des Techniques de Diffusion (INSAS), da Bélgica, a Escuela Internacional de Cine y Television (EICTV), de Cuba, a École Nationale Supérieure des Métiers de l'Image et du Son (FEMIS), da França, entre outras, fez com que Bonfanti ocupasse um lugar de maior destaque entre os profissionais de sua área, refletido nas diversas entrevistas que concedeu a periódicos de cinema, na sua participação em mesas redondas, programas de televisão e rádio ${ }^{7}$ e em homenagens ocorridas quando ainda em vida, como a da Cinemateca Portuguesa, realizada entre os dias 4 e 11 de março de 1985.

Uma das primeiras referências estéticas em matéria de som para Antoine Bonfanti será Boudu sauvé des eaux (1932), de Jean Renoir. Diz ele:

Um filme que me marcou profundamente foi o Boudu sauvé des eaux. O som desse filme é muito moderno. É uma mistura à Godard. Tudo é sujo, tudo se entrechoca, é extraordinário. Ora, quando eu vi o Boudu sauvé des eaux, nem sequer ainda sonhava fazer cinema e o certo é que aquele som já tinha sido feito. (Saguenail e Guimarães 1995, 97)

O filme de Renoir vem a ser um dos vários exemplos de experiências com som direto captado fora dos estúdios no cinema francês dos anos 1930, algo raro em outras cinematografias devido à

2015 e 2016, em que estudamos o trabalho de Antoine Bonfanti no documentário. Essa pesquisa contou com financiamento da Fundação de Amparo à Pesquisa do Estado de Minas Gerais - FAPEMIG.

7 Parte desse material pode ser consultado no acervo da Inatheque:

http://www.inatheque.fr/ (acessado em 18/10/2019). 
pouca praticidade que o método propiciava, pois exigia o uso de caminhões de som. Como lembrou Martin Barnier:

Desde os anos 1930, na França, aconteceram muitas tomadas de som em externas. Les Cinq Gentlemen Maudits, filmado por [Julien] Duvivier em Marrocos, ou mesmo La Chance, realizado por Mirande [sic] em uma floresta de pinheiros na Co `te d'Azur, provaram que o som podia ser registrado fora dos estúdios em 1931. (...) Até a década de 1940, caminhões de som, bastante volumosos, eram necessários para a gravação do som em exteriores (um segundo caminhão servia para fornecer eletricidade). Esses caminhões (por exemplo, os da Tobis $^{8}$ ) permitiam um som de qualidade. Os técnicos de som direto franceses apreciavam particularmente as filmagens fora dos estúdios onde o som possuía uma qualidade superior. (...) A tradição do som direto em exterior real, com o mínimo de pós-sincronização, remonta aos anos 1930. (Barnier 2011, 216)

Em Boudu, vemos o registro de ambiências em uma situação de mundo, quer seja o ambiente silencioso dos cenários montados em estúdio ou os ambientes mais ruidosos das locações e ruas de Paris dos anos 1930, que, em nenhum momento, é escamoteado por Renoir, ocasionando, por diversas vezes, contrastes na faixa sonora entre dois planos, em campo e contracampo, de uma mesma cena - os tais cortes a "golpes de machado", a que Bonfanti se refere em uma outra entrevista (Pimentel e Vasconcelos 1985, 13). O som direto, em Renoir, permite o acesso a registros de ocorrências de mundo que transbordam a tela, o ruído como indicativo do mundo que circunda a tomada, tema caro a toda a escola de som direto. Diz Bonfanti:

Se temos um som com todos os seus estratos, a imagem ganha uma perspectiva enorme, tem uma profundidade tal que, mesmo que seja um close-up, sempre sabemos que há um pássaro que canta a 500 metros de distância. É algo que você sente inconscientemente. (Calzada 2010, 28)

Vale aqui fazer uma ressalva. Muito embora seja considerado um dos iniciadores da moderna escola de som direto francesa, Bonfanti não era um defensor absolutamente radical dessa opção, tal como vamos ver em Jean-Marie Straub, por exemplo. Para ele, o som deveria, antes de tudo, atender as necessidades da narrativa, estando a ela submetida: "Se a tua sequência se situa num lugar calmo e me fazes filmar à beira de uma auto-estrada, é preciso dobrar" (Pimentel e Vasconcelos 1985, 19).

\section{Bonfanti, Vecchiali: o caso Femmes, femmes}

Uma das parcerias mais constantes, ao longo de toda a carreira de Bonfanti, foi com o cineasta Paul Vecchiali, ambos nascidos em Ajácio, na ilha de Córsega. É com Vecchiali que Bonfanti realiza uma das suas

${ }^{8}$ Tobis Klangfilm, companhia produtora e distribuidora alemã com forte atuação entre os anos 1930 e 1940. 
experiências mais interessantes no que diz respeito ao uso do som direto. Trata-se do filme Femmes, femmes, de 1974, quarto longametragem de Vecchiali, filme musical que, de certa maneira, retoma Renoir (cineasta nem tanto admirado por Vecchiali ${ }^{9}$ ) ao homenagear o cinema francês dos anos $1930 .^{10}$

Femmes, femmes narra a história de Sonia e Hélène (interpretadas por Sonia Saviange e Hélène Surgère), duas atrizes decadentes que dividem um apartamento em Paris. Ao longo dos quase cento e vinte minutos de filme, acompanhamos suas desilusões amorosas bem como a luta das duas companheiras na busca pelo dinheiro que as sustente. Em comum, as duas possuem o hábito da bebida servida em doses fartas de champanhe (a dado momento, Hélène vende um aparelho de televisão, sem o consentimento de Sonia, para poder financiar seu vício). ${ }^{11}$ Rodado, em sua maior parte, em locações internas, principalmente o apartamento onde vivem Sonia e Hélène, a estrutura de Femmes, femmes está baseada em cenas longas decupadas em longos planos-sequência. Utilizando um procedimento que era comum no início do cinema sonoro, ${ }^{12}$ Vecchiali recorre a playbacks ao longo das tomadas, que servem tanto para as entradas do acompanhamento musical como para os ruídos. Diz Vecchiali:

Todo o filme foi feito com um play-back musical, certamente, mas que é equilibrado diretamente no set, e as atrizes (ou ator) cantam diretamente no set, com os barulhos do carro que passa, com o barulho do travelling eventualmente. É um som vivo e real. (...) Eu amo sobretudo a realidade da fabricação. (Rabourdin 1975, 109)

\section{Em uma outra entrevista, Vecchiali detalha o procedimento:}

O primeiro plano do filme é um plano de dez minutos no qual há, de uma parte, uma mudança de luz: começa em pleno dia e termina em plena noite, tudo no mesmo plano; quer dizer que os dez minutos de filme representam de fato cinco horas na vida dessas duas personagens, e, em mesmo tempo, elas vivem dentro de um apartamento onde há gente em cima e em baixo. E nós equilibramos, durante esse plano, seis playbacks que representam os ruídos do alto e os ruídos do casal de baixo que discutem. Isso permitiu, durante a tomada, evitar de dizer às atrizes: "Lá em cima acontece alguma coisa, em baixo eles discutem". Elas atuavam sobre coisas que eram verdadeiras, como na vida. Eu creio que, ao nível do plano sequência, nós dificilmente poderíamos fazer de outra forma. Além disso, nós

\footnotetext{
${ }^{9}$ Sobre esse assunto, ver por exemplo: De l'écriture filmique: conversation avec Paul Vecchiali. Disponível em: http://ceciditaubasmot.blogspot.com/2015/07/delecriture-filmique-conversation-avec.html (acessado em 01/05/2018).

${ }_{10}$ Vecchiali manifestou uma admiração quase obsessiva em relação a este período, sobre o qual chegou a organizar uma enciclopédia (Vecchiali 2010).

${ }^{11} \mathrm{O}$ filme se destacou, na extensa filmografia de Vecchiali, por atrair a atenção dos críticos, tais como Pier Paolo Pasolini que, em função da exibição do filme na Bienal de Veneza, acabou convidando Sonia Saviange e Hélène Surgère para atuarem em Salò, ou os 120 dias de Sodoma (1975). Sobre esse assunto, ver, por exemplo, Carbonnier $(1983,14)$.

${ }^{12}$ Sobre esse assunto, ver, por exemplo, Daney $(2001,34)$.
} 
filmamos em som direto. (...) Era preciso, portanto, não somente colocar os microfones mas também poder movimentar com a vara sem que a gente visse sua sombra. E mais, era preciso, de uma parte, executar o playback no exato momento pretendido e, enfim, equilibrar a ligação de som, o nível do som do playback e do som direto. (Cornand e Lajeunesse 1974, 80)

$\mathrm{Na}$ mesma entrevista, Antoine Bonfanti também comenta sobre o processo de captação:

Era uma mixagem em direto sobretudo para os playbacks de ruídos. Para os playbacks de música, eu tentei fazer um balanço que eu sempre podia compensar depois na mixagem. O que significa que eu deveria ter sempre a voz bastante presente. Posto que, contrariamente ao disco, se a gente canta no cinema, é necessário que nós compreendamos, é necessário que as letras cantadas não fiquem abaixo da música. Eu posso sempre adicionar a música na mixagem mas eu não posso removê-la. Portanto era necessário encontrar um equilíbrio em direto entre os playbacks, os alto-falantes, a cantora ou cantor, para que pudéssemos assim trabalhar. (Cornand e Lajeunesse 1974, 80-82)

Assim, em Femmes, femmes, temos a captação não apenas do ruído natural da cena, mas também de ruídos fabricados para a cena ruídos esses que nem sempre possuem pertinência dramática. Vecchiali insiste no valor de verdade do som direto e na valorização da autenticidade da atuação, ou seja, nas suas palavras, numa "fabricação completamente realista" (Cornand e Lajeunesse 1974, 82), desse modo se aproximando da noção de realismo cara a André Bazin (2014, 83-94).

É como se Vecchiali propusesse ao espectador um exercício de escuta que abarcasse diversas formas de ruído, bastante incomuns quando se trata de som de filme e que muitas vezes passam despercebidas ao espectador. Em Femmes, femmes, os ruídos adquirem estatuto próprio, rompendo uma relação harmônica de mise-en-scène e tomando, muitas vezes, a forma de elementos estranhos que invadem o ambiente sonoro. De fato, a própria noção de ruído necessita ser questionada, já que vem a ser pouco precisa. Como lembra Chion (2011, 115): "Durante muito tempo, os ruídos foram os esquecidos do som no cinema, não só na sua prática, mas também na análise.” A prática comum das análises do som dos filmes trabalha invariavelmente com uma classificação dos sons entre voz (ou diálogos), música e ruídos, sendo os ruídos aquele gigantesco conjunto de sons que não podem ser classificados nem como voz nem como música. Essa classificação é também frequentemente usada nos processos de edição de som, conforme lembra Virginia Flôres:

Trata-se de uma classificação baseada somente no que pode ser encontrado ao se assistir à maioria dos filmes, feita por quem parte da obra pronta. Para simples fruição da obra cinematográfica, não se torna necessário uma maior segmentação destes elementos sonoros, mesmo porque, depois do filme pronto, é muito difícil o som de um 
filme ser compreendido como objetos sonoros isolados. (Flôres 2013, 118)

Outra definição frequente de ruído vem a ser aquela que o relaciona a sons indesejáveis, ou àqueles sons que provocam certo tipo de incômodo, efeito que as artes de vanguarda desde cedo souberam trabalhar como valor estético (Kahn 2001). Essa percepção de incômodo pode estar ligada às propriedades do som como frequência, timbre e volume, como sublinha José Miguel Wisnik:

$\mathrm{O}$ ruído é aquele som que desorganiza outro, sinal que bloqueia o canal, ou desmancha a mensagem, ou desloca o código. A microfonia é ruído, não só porque fere o ouvido, por ser um som penetrante, hiperagudo, agressivo e "estourado" na intensidade, mas porque está interferindo no canal e bloqueando a mensagem. Essa definição de ruído como desordenação interferente ganha um caráter mais complexo em se tratando de arte, em que se torna um elemento virtualmente criativo, desorganizador de mensagens/códigos cristalizados e provocador de novas linguagens. (Wisnik 2002, 33)

Femmes, femmes é um filme feito a partir de um roteiro com rigor dramático, que tem no diálogo o eixo principal de sustentação da ação. Com isso, a voz é elemento de destaque no quadro sonoro, sendo em torno dela que toda a captação direta do som se orientou na filmagem. No entanto, as vozes são captadas em situação de mundo, mais precisamente, no interior de apartamentos e arredores situados em uma região central de Paris povoada por sons urbanos (temos apenas uma cena externa). Não separar a captação das vozes das condições acústicas que as envolvem é condição essencial para o projeto realista de Vecchiali. Nesse conjunto, o ruído mantém seu caráter de som periférico, espécie de moldura sonora para as vozes, mas possuindo importância fundamental na composição estética do filme.

Pelo fato de ocuparem aquele gigantesco grupo de sons não associados à música e vozes, a classificação dos ruídos não é tarefa simples. Alguns desses sons, no entanto, se destacam de outros. O turturinar, acompanhado do bater de asas, de pombos, o canto de pássaros, o vozerio de vizinhos, portas que batem, o ranger dos assoalhos de madeira, o ruído de automóveis que passam e invadem os espaços internos quase no mesmo nível de volume dos diálogos são sons que sinalizam eventos que possuem existência apenas no espaço fora de campo e que, em quase nenhum momento, são aludidos por qualquer um dos personagens ou pela narrativa que se desenrola. Soma-se àquilo que poderíamos chamar de ruídos de fundo, que habitam apenas o espaço fora de campo, os ruídos fabricados pela própria movimentação dos atores, que podemos chamar de ruídos de cena. Todas as ações são marcadas por um barulho intenso, quer seja em função da materialidade do cenário (como piso, portas, mesas, etc.) e dos objetos de cena manuseados pelos atores (garrafas, copos, papéis, roupas, etc.) quer seja pelas condições acústicas dos ambientes internos que ampliam a reverberação dos sons produzidos. Sobre a 
necessidade de adequação do cenário e objetos de cena às demandas de captação do som direto, o técnico de som João Godoy afirma:

Quando o som direto e valorizado, as cenas potencialmente ruidosas são planejadas conjuntamente pelas áreas técnicas envolvidas com o objetivo de encontrar soluções que satisfaçam as suas necessidades. Cenas do cotidiano doméstico, com os personagens preparando ou realizando alguma refeição, por exemplo, são frequentes e muito problemáticas para a captação do som direto. A manipulação de utensílios de cozinha de metal e de vidro (panelas, pratos, talheres) geram intensos ruídos e são desastrosos para a captação de diálogos simultâneos. A solução para a realização de cenas como essas envolvem, entre outros procedimentos: uma decupagem adequada; a atenção dos atores para o momento exato entre a execução das ações e a emissão das falas; a escolha de objetos de cena que contribuam com a minimização dos ruídos. (Souza 2010, 107)

Femmes, femmes parece não seguir a lógica desse ajuste do ambiente às necessidades de captação do som direto, como se aceitasse o cenário e objetos de cena nas condições rigorosamente em que se encontram como forma a preservar (ou aumentar) o realismo da filmagem. O filme chama a atenção para o ruído dos pisos de madeira dos apartamentos, bastante audível nas cenas, quer seja pela movimentação dos atores (ruídos de cena), mas até mesmo pela movimentação da equipe de filmagem (ruídos de fundo), como na cena em que Hélène e Sonia conversam sentadas em uma pequena varanda do apartamento com a tomada de câmera e som ocorrendo dentro do apartamento. Na cena é possível ouvir, de maneira clara, o ranger das tábuas do assoalho denunciando uma equipe de filmagem a se movimentar no ambiente interno, fazendo um travelling de aproximação que, ao final, irá revelar um cemitério localizado bem ao lado do apartamento de Sonia e Hélène (o cemitério de Montparnasse, em Paris), visto ao fundo através da janela. Neste exemplo, os ruídos de fundo servem também para integrar, na trilha sonora, a equipe de filmagem a fabricar um filme.

Outro bom exemplo de uma cena que explora bem esse excesso de ruídos, resultado da soma dos ruídos de fundo com os ruídos de cena, é a cena em que Hélène vai limpar o apartamento de seu vizinho Ferdinand, interpretado por Noël Simsolo, ator que também assina o roteiro do filme. No início da cena, ouvimos novamente, dentro de um ambiente interno, os tais pombos se manifestando fora de campo - os mesmos que já haviam manifestado existência em cena anterior, que se passava no interior do apartamento de Hélène e Sonia. Após uma breve conversa inicial, em que comentam a partida da mulher de Ferdinand e o fim do casamento deste, Hélène veste um avental e liga um aspirador. Ao fazê-lo, Hélène diz: "Falta música aqui." Nesse mesmo instante, o telefone toca de forma ruidosa e Ferdinand passa a gritar sem conseguir escutar o que está sendo dito do outro lado da linha. Mais tarde, Hélène, impossibilitada de usar o aspirador por conta das conversas de Ferdinand ao telefone, passa a martelar as teclas de um piano, que ocupa o centro da sala, de maneira tediosa. 
Mais uma vez, Ferdinand solicita a ela que faça silêncio. Hélène desiste da limpeza e passa a se arrumar para sair, fazendo isso de forma também bastante ruidosa. A sequência termina com mais um número musical cantado por Hélène, em que o acompanhamento entra de fundo, em playback, sem se sobrepor totalmente aos ruídos da cena. Sobre essa sequência, diz Vecchiali:

Esse é um plano-sequência bastante longo. Durante cinco minutos, ela discute com Noël Simsolo, que faz o papel de Ferdinand, e depois desses cinco minutos a música entra, e ela canta. É bastante evidente que sua voz está carregada de tudo aquilo que precedeu, não é um playback perfeito que ela gravou dois meses antes que não tivesse nenhuma ligação com a cena. Eu deixei a atriz se soltar até a canção, e eu creio que ela, naquele momento, carregue toda a potencialidade da cena que passa na canção e que talvez traga notas falsas, que eu não me importo, que traga sobretudo uma realidade da fabricação. (Rabourdin 1975, 109)

\section{Entre dois modelos}

O tratamento dado ao som no filme de Vecchiali, e a própria insistência do diretor em afirmar o caráter realista de sua fabricação, levanta, de certa maneira, uma questão bastante presente, não apenas no trabalho de captação de som direto, mas de todo o tratamento do som no cinema, que gira em torno de uma concepção hierárquica dos sons. James Lastra (2000) comenta sobre a oposição entre dois modelos de representação de som, ainda no período inicial de desenvolvimento das técnicas de registro sonoro - um modelo que preza a inteligibilidade versus um modelo que preza a fidelidade:

Os dois modelos gerais de captação de som que dominaram - e continuam a dominar - ideias técnicas sobre a representação do som poderiam ser chamados de modelo fonográfico (ou de percepção fiel) e de modelo telefônico (ou de inteligibilidade). (Lastra 2000, 138-139)

Segundo Lastra, o princípio básico adotado pelo modelo fonográfico advoga o respeito às especificidades acústicas do ambiente de gravação (fidelidade) seja quais forem as condições desse ambiente. O modelo telefônico tem por característica a valorização de inteligibilidade e clareza do discurso em detrimento das condições acústicas do ambiente de gravação (Lastra 2000, 139). Inerente a ambas as concepções está o critério de hierarquia entre as classes de sons a serem captadas, como vozes, músicas e ruídos. Diz ele:

A concepção de fidelidade assume que todos os aspectos do evento sonoro são inerentemente significantes, inclusive longos ou curtos tempos de reverberações, proporções de sons diretos para refletidos, ou mesmo certas peculiaridades dos locais de performance. A concepção telefônica, não apenas limitada a telefones e vozes, assume que o som possui uma hierarquia intrínseca que torna alguns aspectos essenciais e outros não tanto. (Lastra 2000, 139) 
Muito embora o debate em torno do som de cinema tenha alcançado termos de reconciliação e adaptação entre essas duas variáveis, que levaram em conta aspectos específicos das necessidades dramáticas e narrativas do filme, bem como critérios de continuidade, essas concepções ainda permanecem muito presentes na forma de se pensar o som do filme. De um lado, temos uma concepção que preza sempre o som limpo, puro, absolutamente controlado, trabalhado preferencialmente em pós-produção e em que predomina o trabalho do sound designer, cuja figura máxima está em Walter Murch ${ }^{13}$. Essa concepção é bastante presente nos manuais técnicos de som, como, por exemplo, o de Tomlinson Holman:

Na maioria dos casos, o som de filme e televisão para programas de entretenimento e documentário é construído na pós-produção por profissionais que utilizam muitos pedaços de som misturados perfeitamente juntos para criar um todo. (Holman 2002, xvii)

Umas das consequências dessa concepção de som controlado e limpo vem a ser a valorização de um hiper-realismo sonoro. Segundo Holman, esse hiper-realismo teria por definição tratamentos sonoros marcados por um "exagero da realidade" (Holman 2002, xviii) em que os sons adquirem uma dimensão pouco naturalista no sentido em que todos os sons que são inseridos em uma trilha sonora são inseridos para serem ouvidos de maneira destacada, dentro de uma noção de funcionalidade. A preocupação com a inteligibilidade permanece bastante presente dentro dessa concepção controlada de som, que descarta os efeitos do acaso ${ }^{14}$.

Uma outra concepção, bem menos apreciada pelos manuais e cineastas, vem ser aquela que valoriza o som direto com todas as suas imperfeições e impurezas, mas com seu valor de "verdade", de um som único que não se repete. Essa concepção estará intimamente associada a um código de representação realista de som, o que Jay Beck (2016) chama de "áudio-vérité". Ao abrir o microfone para o mundo, principalmente em situações que envolvem filmagens em externas, o cineasta incorpora no projeto sonoro do filme o risco da captação de sons que não estarão necessariamente integrados nas necessidades da narrativa. São aqueles sons que Chion $(2011,87)$ chama de "sons-em-si", que existem por si mesmos:

O risco destas intrusões sonoras espontâneas, numa rodagem em som direto, é o de darem a uma palavra do diálogo ou a um gesto do ator um sentido particular, não desejado, mesmo que enquanto pontuações aleatórias: uma motorizada que acelera fora de campo, um rádio ou uma televisão cujo som passa pelas janelas podem não só cobrir o texto, mas também dar-lhe um valor diferente. (Chion 2011, 86)

\footnotetext{
${ }^{13}$ Montador e sound designer americano conhecido por seu trabalho com Francis Ford Coppola em filmes como The conversation (1974) e Apocalypse now (1979).

${ }^{14}$ Sobre esse assunto, ver por exemplo Costa (2011).
} 
Vale ressaltar, no entanto, que boa parte do apelo no trabalho de captação de som direto está justamente em assumir esses riscos e nas possibilidades únicas que os acontecimentos sonoros ditados pelo acaso podem trazer ao filme. Para Bonfanti:

Existem coisas que se passam na frente de um microfone que nós somos verdadeiramente incapazes de reproduzir na mixagem. Não é apenas colocando três sons de automóveis que nós criamos uma circulação, isso não é verdade. E mais ainda, nós não temos a profundidade. Existem os planos sonoros, que são muito difíceis de reproduzir. E a acústica é muito importante. (Cornand e Lajeunesse 1974, 76)

É sempre bom lembrar que o trabalho de captação de som direto pode ser feito, e muitas vezes é-o, com o uso de microfones de lapela sem fio, que estabelecem uma perspectiva fixa em relação à fonte da voz, aumentando o grau de inteligibilidade na captação. Sobre o trabalho de captação de som direto, Godoy afirma:

Durante a década de 1970, a evolução da tecnologia e a miniaturização dos sistemas eletrônicos permitiram o desenvolvimento dos microfones de lapela, os quais podiam ser ocultados no corpo dos atores, geralmente sob a roupa, enviando o sinal de áudio ao gravador através de um sistema de radiotransmissor sem a necessidade de conexão física via cabos. Por isso, ficaram conhecidos como "microfones de lapela sem fio" (wireless microphone). No processo de realização do cinema convencional, o desenvolvimento destes dispositivos permitiu a superação da tradicional condição imposta ao som direto pelo posicionamento do microfone fora do quadro estabelecido pela câmera. Como usualmente os microfones não deveriam ser revelados em campo, o seu posicionamento era dependente da imagem. Com os microfones de lapela sem fio, a demanda pela captação das falas com sonoridade de contínuo close-up, manifestada desde os primórdios do cinema sonoro, pode ser satisfeita, mantendo o microfone constantemente próximo a fonte sonora independentemente do tamanho do quadro definido pela câmera. (Souza 2010, 72)

O uso desses microfones, apesar de bastante frequente, nem sempre é bem-vindo por técnicos de som direto justamente por minimizarem o aspecto de fidelidade do evento sonoro, diminuindo os efeitos de reverberação do espaço onde o ator está inserido. O técnico de som direto Pierre Gamet comenta este aspeto:

Hoje, a voz é mais e mais presente, precisa, fina, mas há uma pequena ausência. Nossa orelha se habituou a esta precisão, a esta qualidade. Nós não podemos mais fazer o som direto como antes, os diretores incorporaram as novas técnicas e nós somos obrigados a compor com elas. Escutar as palavras do ator muito presentes, captadas por um microfone de lapela se tornou uma convenção, está dentro das orelhas de todos os diretores. Existe uma uniformização. (Nougaret e Chiabaut 1997, 67) 
Esta uniformização na captação do som direto está diretamente ligada a uma vocação do cinema centrada na voz a que Chion (2011, 13) chama de "vococêntrica", que minimiza a participação criativa do técnico de som direto no tratamento do som do filme (Souza 2010, 96) e passa a valorizar o trabalho feito em pós-produção. Éric Devulder, outro dos destacados nomes do som direto francês, manifestou o desejo de reverter essa situação:

Meu sonho é de fazer um filme simplesmente com a vara de boom, com os microfones acima dos atores. E que isso seja suficiente. Esses filmes já existem, mas são raros. Sobre o plano acústico, a modulação com a vara é bem mais bela, mas às vezes isso prejudica a movimentação dos atores. (Nougaret e Chiabaut 1997, 80)

\section{A apoteose do ruído}

No filme de Vecchiali, percebemos a predominância do som direto na relação com os sons sobrepostos em pós-produção. Essa predominância marca o aspecto realista do som, como o próprio Vecchiali afirma, ao valorizar o som obtido em tomadas longas e sincrônicas, dentro de uma concepção próxima à de Bazin marcada pelo respeito à continuidade do evento filmado ${ }^{15}$.

A fidelidade ao som direto realça os efeitos de descontinuidade entre planos de imagem e som encadeados dentro de uma mesma cena. Um exemplo que deixa bastante evidente esse efeito de descontinuidade é a cena que se passa no interior do apartamento das duas atrizes, pontuada pela entrada de um médico, interpretado por Michel Delahaye, chamado para atender Sonia. Ao chegar no apartamento, sendo recebido por Hélène, o médico relata o estado de saúde de uma vizinha, Madame Durand, que sofre de sífilis e está em estado terminal. Seu relato é coberto, no início, por um plano de conjunto que enquadra, em plano americano, o médico e Hélène. Dentro desse plano, temos um insert de um primeiro plano do médico. Embora se mantenha a exata continuidade do relato, o som de sua voz entra de forma descontínua, estando esta bem mais próxima (em volume) e menos reverberada do que no plano anterior, consequência direta do tipo de enquadramento que possibilita o posicionamento do microfone mais próximo da fonte sonora. Na esteira de Bazin, percebemos que o respeito pela duração do evento, registrado pela câmera, graças à adoção de planos longos e pela consequente minimização da montagem, se torna ainda mais presente pela manutenção dos planos sonoros absolutamente sincrônicos. Vemos

\footnotetext{
${ }^{15}$ Nas palavras de Ismail Xavier, extraídas do texto de apresentação de Bazin: "A forma desse realismo tem seus procedimentos-chave. Esses mesmos que os construtores do cinema moderno (Renoir, Welles, Wyler, Rossellini) estavam, ao ver de Bazin, afirmando, a par da diversidade de circunstâncias e 'mensagens': o 'plano-sequência' (apresentação da cena sem cortes numa única tomada), os movimentos de câmera, o uso da profundidade do campo visível (tridimensionalidade), o respeito à duração contínua dos fatos, a minimização dos efeitos de montagem." (Bazin 2014, 19)
} 
assim que a minimização da montagem ocorre no que diz respeito tanto à faixa imagem como à faixa sonora.

Ao final, o filme vem a reservar, como clímax, uma espécie de apoteose do ruído, e da distorção. Depois de terem sua situação financeira regularizada por uma herança deixada por Julien, exmarido de Hélène, Sonia e Hélène se servem de um jantar de gala à luz de velas com comidas e bebidas fartas. Ao final do jantar, Sonia passa a sentir fortes dores no estômago, o que a faz deixar seu lugar na mesa indo se apoiar na parede se contorcendo de dor e gritando de maneira desesperada. Por um momento, Hélène tenta ajudá-la, mas acaba, ao final, apenas se mantendo como espectadora passiva do drama de sua amiga. No último plano do filme, vemos Hélène, em plano médio, tomando champanhe, estando Sonia fora de quadro. A câmera recua, com Hélène ainda ocupando o centro do plano, e os gritos agonizantes e estridentes de Sonia dominando o campo sonoro. O que era para ser um happy end, de acordo com a cena anterior, que mostrara o recebimento da herança, acaba de maneira melancólica e sombria. O ruído dos gritos de Sonia atinge elevados níveis de saturação, algo com que Bonfanti lidava de maneira peculiar: "Por mim, deixo-os 'gritar' à vontade. (...) As cordas vocais já estão saturadas, quando gritamos, a fita magnética também pode estar" (Pimentel e Vasconcelos 1985, 22-23).

\section{Conclusão}

Ao trazermos para um primeiro plano de interesse o trabalho de Antoine Bonfanti em Femmes, femmes, procuramos, ao longo desse artigo, demonstrar a importância do papel do técnico de som entendido também como um profissional de criação. O som de Femmes, femmes, resultado do rico intercâmbio de ideias estabelecido entre Bonfanti e Paul Vecchiali, explora, de maneira radical, as qualidades do som direto. Dentro do contexto atual, com todas as potencialidades do som digital 5.1, sua alta gama de frequências e canais, o som de Femmes, femmes poderia muito bem ser considerado de baixa qualidade, um som ruim, próximo a uma experiência amadora. Femmes, femmes certamente também não se encaixaria dentro da lógica de exibição de mercado, com suas salas multíplex próprias para realçar o som hiper-realista das produções de Hollywood. Compreender o som de Femmes, femmes envolve necessariamente conhecer o contexto de sua realização e principalmente a forma de pensar o som de filme do técnico de som Bonfanti, principal nome de toda uma escola de som direto na França, cuja influência se estende até às produções contemporâneas, como bem lembra Michel Marie (2013), a propósito da influência do documentário direto canadense no cinema de ficção francês. Antes de ser um som "ruim", pois incorpora os ruídos e a reverberação dos ambientes internos e externos, além dos ruídos causados pela manipulação dos objetos de cena e pela movimentação dos atores, o som do filme de Vecchiali é marca de um estilo que poderíamos chamar de realista, ou de áudio-vérité, para retomarmos a expressão 
de Jay Beck. Essa escola realista de som direto, como já comentamos, ganha novo impulso com o advento dos gravadores magnéticos portáteis nos anos 1960, o que irá impactar toda uma produção de documentários para depois ser incorporada aos filmes de ficção. Como destacamos, na França, essa escola tem suas origens ainda nos primórdios do cinema sonoro, notadamente com Jean Renoir, cuja primeira experiência foi La chienne (1931). Sobre esse filme, Dudley Andrew afirma:

Com La Chienne, como André Bazin bem apontou, o som se tornou o complemento natural para o estilo realista que Renoir estava procurando intermitentemente durante os anos 1920. Isso permitiu a ele se tornar 'o mais francês dos diretores' e a aproximá-lo de um mundo mais concreto que ressoava com sons, sons que carregavam sotaques e timbres distintivos. (Andrew 1980, 107)

\section{Ou, nas palavras do próprio Bazin:}

A trilha sonora de La Chienne é consistentemente excelente graças à gravação em locações. Os ruídos atmosféricos são fantásticos porque são reais. Por exemplo, o diálogo romântico entre Legrand e Lulu abaixo de seu apartamento é acompanhado pelo barulho da água na sarjeta. Por outro lado, a música do cantor de rua foi claramente gravada em estúdio. Mesmo nas cenas que consistem completamente em diálogos, que foram filmadas em estúdio, o som é realista. Quando um personagem se distancia, nós o sentimos indo embora: isso não é efeito técnico. (Bazin 1974, 28)

Em Femmes, femmes, Vecchiali faz uma homenagem explícita ao cinema francês de Renoir, Grémillon, Pagnol, Duvivier e Clair dos anos 1930, um período em que a produção francesa chega a rivalizar com a de Hollywood e a da Alemanha. Essa homenagem vem expressa não apenas pela escolha de seu recorte temático, mas sobretudo pelo estilo de som adotado para o filme. Seguindo os ensinamentos de Bonfanti, o filme de Vecchiali se abre para a captação em direto de uma ampla possibilidade de sons do mundo, dos prováveis aos mais improváveis, cuja característica principal é a de serem sons únicos, singulares, sons que não vamos mais encontrar em qualquer outro filme, ou nas bibliotecas de sons, como os gritos saturados de Sonia, ou os onipresentes pombos que se manifestam fora de campo. Essa foi uma das contribuições de Bonfanti para o pensamento do som de cinema, a busca de um som único diferente para cada filme, como ele mesmo afirma:

O nosso ofício do som deve ser assumido como um trabalho totalmente pessoal e subjetivo que deve condizer com o filme para o qual trabalhamos. Não se faz "cinema", faz-se sempre um filme. Cada vez que começamos um filme temos medo como o ator antes de pisar o palco. (...) É sempre uma aventura extraordinária e uma experiência que só se pode viver subjetivamente. Quantas pessoas tentaram copiar ou utilizar reminiscências de grandes realizadores ou músicos? Nunca conseguiram igualá-los ou substituí-los. Só podemos ser nós próprios. (...) O interesse da nossa profissão é 
sermos obrigados à renovação. Somos obrigados a pensar de forma diferente em função do que se passa à nossa frente e à nossa volta $\mathrm{e}$ da história que se está a contar... (Saguenail e Guimarães 1995, 93)

Como se seguisse estes conselhos, após a realização de Femmes, femmes, Vecchiali partirá para um projeto bastante ousado, do ponto de vista de seu conteúdo temático - o filme Change pas de main (1975), que explora o universo da pornografia dentro de uma trama policial, sendo este um dos raros filmes de Vecchiali a não contar com o nome de Bonfanti nos créditos. Após a realização de Change pas de main, Vecchiali dará início à sua rica experiência com a produtora Diagonale, juntamente com os cineastas Jean-Claude Biette, Jean-Claude Guiguet, Noe "1 Simsolo e Marie-Claude Treilhou ${ }^{16}$, que lhe permitiu manter, a partir dos anos 1970, uma produção regular de longas-metragens, mesmo ocupando uma posição periférica no cinema francês. No entanto, a experiência no campo sonoro de Femmes, femmes nunca mais se repetiu na carreira de Vecchiali.

Antoine Bonfanti manteve sua parceria com Paul Vecchiali em filmes como La machine (1977), Corps à coeur (1979), C'est la vie! (1980), Rosa la rose, fille publique (1986), Encore (1988), filmes que ajudaram a enriquecer sua extensa filmografia, marcada por uma abertura a experiências em países diversos com destaque para a sua significativa contribuição para o cinema português, trabalhando ao lado de nomes como António-Pedro Vasconcelos, Saguenail, Fernando Lopes, Margarida Cordeiro, António Reis, Margarida Gil e Rita Azevedo Gomes.

\section{BIBLIOGRAFIA}

Andrew, Dudley. 1980. "Sound in France, the origens of a native school.” In Cinema/Sound, organizado por Rick Altman. New Haven: Yale French Studies.

Barnier, Martin. 2011. "Les premiers ingénieurs du son français." 1895. Mille huit cent quatre-vingt-quinze, 65. URL: http://journals.openedition.org/1895/4445; DOI: 10.4000/1895.4445.

Bazin, André. 2014. O que é cinema? São Paulo: Cosac Naify.

-----. 1974. Jean Renoir. London, New York: W. H. Allen.

\footnotetext{
${ }^{16}$ Sobre esse assunto, ver, por exemplo, artigo "La ligne diagonal", de Philippe Azoury, disponível em: https://next.liberation.fr/cinema/2006/01/04/la-lignediagonale 25377, acessado em 01/02/2018.
} 
Beck, Jay. 2016. Designing sound, audiovisual aesthetics in 1970 s American cinema. New Brunswick, New Jersey, London: Rutgers University Press.

Calzada, Víctor Fowler. 2010. "Antoine Bonfanti y su médio siglo de sonidos." En foco, \#26, ano 03, 2010, San Antonio de los Baños, 26-30.

Carbonnier, Alain. 1983. "Dossier-auteur, Paul Vecchiali." Cinéma, \#298, oct, 1983, 11-26.

Chion, Michel. 1985. Le son au cinema. Paris: Cahiers du Cinema/Editions de l'Etoile.

-----. 2002. Technique et création au cinéma, le livre des images et des sons. Paris: ESEC Edition.

----. 2011. A audiovisa o. Lisboa: Texto \& Grafia.

Cornand A., e J. Lajeunesse. 1974. “Anoine Bonfanti.” Image et son, la revue du cinema, \#285, Juin/Juille, 1974, 73-82.

Costa, Fernando. 2011. "Pode-se dizer que há algo como um hiperrealismo sonoro no cinema argentino?" C-Legenda Revista do Programa de Pós-graduação em Cinema e Audiovisual - Universidade Federal Fluminense 1(24): 84-90.

Daney, Serge, et al. 2001. La politique des auteurs, les entretiens. Petite bibliothèque des Cahiers du cinéma, \#47. Paris: Cahiers du Cinéma.

Flôres, Virginia. 2013. O cinema, uma arte sonora. São Paulo: Annablume.

Gauthier, Guy, et al. 2003. Le documentaire passe au direct. Montreal: VLB Éditeur.

Holman, Tomlinson. 2002. Sound for film and television. Boston: Focal Press.

Kahn, Douglas. 2001. Noise, water, meat, a history of sound in the arts. Cambridge, London: The MIT Press.

Lastra, James. 2000. Sound technology and the american cinema, perception, representation, modernity. New York: Columbia University Press.

Mamber, Stephen. 1974. Cinema verite in America, studies in uncontrolled documentary. Cambridge, Massachusetts, London: The MIT Press.

Marie, Michel. 2013. "Quebec - França, voltas, reviravoltas, vaivéns nas duas direções." Rebeca, revista brasileira de estudos de cinema e audiovisual 2(4), jul-dez.

Marsolais, Gilles. 1974. L'aventure du cinema direct. Paris: Éditions Seghers.

Neves, David. 1966. “A descoberta da espontaneidade: Breve histórico do cinema-direto no Brasil.” In Cinema moderno, 
cinema novo, organizado por Flávio Moreira da Costa. Rio de Janeiro: José Alvaro Editor.

Nougaret, Claudine, e Sophie Chiabaut. 1997. Le son direct au cinema. Paris: FEMIS.

Pimentel, V., e A. Vasconcelos. 1985. "Encontro com Antoine Bonfanti." Antoine Bonfanti, homenagem a um técnico de som, 11-35. Cinemateca Portuguesa, Março, 1985.

Rabourdin, Dominique. 1975. "Paul Vecchiali (Femmes, femmes)." Cinéma, \#194, Janvier, 1975, 106-113.

Saguenail, e R. Guimarães. 1995. "Conversa com Antoine Bonfanti." A grande ilusão, revista de cinema, número 18-19, novembro: 91-106.

Segura, S., e S. Mouriès. 2005. "La grande aventure du cinéma c'est le son." Ina, les nouveaux dossiers de l'audiovisuel, \#31, fév-mars: 41-42.

Souza, Joaõ Baptista Godoy. 2010. Procedimentos de trabalho na captac $a^{\sim}$ o de som direto nos longas-metragens brasileiros Contra todos e Anto ^nia: a técnica e o espac o criativo. Tese de Doutorado - Universidade de São Paulo. São Paulo.

Vecchiali, Paul. 2010. L'encinéclopedie: cinéastes franc a ais des anneés 1930 et leur oeuvre. Paris: Editions de l'Oeil.

Wisnik, Jose Miguel. 2002. O som e o sentido. Saõ Paulo: Cia. das Letras.

\section{FILMOGRAFIA}

Antoine Bonfanti, traces sonores d'une écoute engagée. Dir. Suzanne Durand. Le Mur du son cinéma, Saint-Louis production, France 3 Corse, França, 2002.

Apocalypse Now. Dir. Francis Ford Coppola. Zoetrope, EUA, 1979.

Boudu sauvé des eaux [longa-metragem] Dir. Jean Renoir. Les Productions Michel Simon, França, 1932.

C'est la vie! Dir. Paul Vecchiali. Diagonale, França, 1980.

Change pas de main. Dir. Paul Vecchiali. Contrechamp, Unité Trois, França, 1975.

Corps à coeur. Dir. Paul Vecchiali. Diagonale, França, 1979.

Encore. Dir. Paul Vecchiali. Diagonale, La Sept, França, 1988.

Femmes, femmes. Dir. Paul Vecchiali. Unité 3, França, 1974.

India song. Dir. Marguerite Duras. Les Films Armorial Sunchild Productions, França, 1975.

La chienne. Dir Jean Renoir. Films Jean Renoir, França, 1931.

La jetée. Dir. Chris Marker. Argo Films, França, 1963. 
La machine. Dir. Paul Vecchiali. Diagonale, França, 1977.

Le joli mai. Dir. Chris Marker, Pierre Lhomme. Le Sofra, França, 1963.

Muriel. Dir. Alain Resnais. Argo Films, França, 1962.

Pierrot le fou. Dir. Jean-Luc Godard. Films Georges de Beauregard, Rome Paris Films, Société Nouvelle de Cinématographie (SNC), França/Itália, 1965.

Rosa la rose, fille publique. Dir. Paul Vecchiali. Diagonale, Périphérie Production, Stéphan Films, França, 1986.

Salò o le 120 giornate di Sodoma. Dir. Pier Paolo Pasolini. Produzioni Europee Associate, Les Productions Artistes Associés, Itália/França, 1975.

The Conversation. Dir. Francis Ford Coppola. American Zoetrope, EUA, 1974. 